\title{
A quick and inexpensive method to quantify spatially variable infiltration capacity for artificial recharge ponds using photographic images
}

\author{
Daniele Pedretti ${ }^{\mathrm{a}, *}$, Marco Barahona-Palomo ${ }^{\mathrm{b}}$, Diogo Bolster ${ }^{\mathrm{c}}$, Xavier Sanchez-Vila ${ }^{\mathrm{a}}$, \\ Daniel Fernàndez-Garcia ${ }^{\mathrm{a}}$ \\ ${ }^{a}$ GHS - Hydrogeology Group, Department of Geotechnical Engineering and Geosciences, Universitat Politècnica de Catalunya (UPC) - BarcelonaTech, 08034 Barcelona, Spain \\ ${ }^{\mathrm{b}}$ GHS - Hydrogeology Group, Department of Geosciences, Institute of Environmental Assessment and Water Research (IDAEA-CSIC), 08034 Barcelona, Spain \\ ${ }^{\mathrm{c}}$ Environmental Fluid Dynamics Laboratories, Department of Civil Engineering and Geological Sciences, University of Notre Dame, IN, USA
}

\section{A R T I C L E I N F O}

\section{Article history:}

Received 3 April 2011

Received in revised form 8 January 2012

Accepted 2 February 2012

Available online 14 February 2012

This manuscript was handled by Andras

Bardossy, Editor-in-Chief, with the

assistance of Luis E. Samaniego, Associate Editor

\section{Keywords:}

Managed artificial recharge

Surface ponds

Infiltration capacity

Spatial variability

Clogging

Satellite images

\begin{abstract}
S U M M A R Y
The efficiency of artificial surface ponds (SPs) for managed aquifer recharge (MAR) is mostly controlled by the topmost portion of the soil. The most significant soil property controlling recharge is the infiltration capacity $\left(I_{c}\right)$, which is highly variable in space. Assessing its spatial distribution in detail is prohibitive in practice due to high costs, time effort, and limited site accessibility. We present an alternative method for a quick and low-cost quantitative estimation of the spatial distribution of $I_{c}$ based on satellite images. The fact that hydraulic properties of topsoils and color intensities of digital images depend on some common factors such as moisture content, nature and organization of grains, proportion of iron, and organic and clay content among others, allow us to infer infiltration capacities from color intensities. The relationship between these two variables is site specific and requires calibration. A pilot SP site in Catalonia (Spain) is used as an application example. Two high-resolution digital images of the site are provided at no cost by the local cartographic institute as well as from a popular Internet-based map server. An initial set of local infiltration experiments, randomly located, were found to correlate to color intensities of the digital images. This relationship was then validated against additional independent measurements. The resulting maps of infiltration were then used to estimate the total maximum infiltration of the artificial pond area, the results being consistent with an independent flooding test performed at the site.
\end{abstract}

(c) 2012 Elsevier B.V. All rights reserved.

\section{Introduction}

Managing water resources under scarcity is a necessity in many arid and semiarid regions worldwide (Bouwer, 2002; Scanlon et al., 2006; Gee and Hillel, 1988; Gale, 2005). Amongst the many practices that exist to increase groundwater availability as well as to improve water quality in a given area, artificial or induced recharge practices (ARs) are viable options (Greskowiak et al., 2005; Jha et al., 2009; Dillon, 2002). A common system to induce recharge is via excavated surface ponds (SPs). These facilities are popular in developed and developing countries (e.g. Hofkes and Visscher, 1986; Asano, 1985; Cheng et al., 2009; Ting et al., 2002; Stonestrom et al., 2007; Aish and de Smedt, 2004; O'Shea et al., 1981; Tuinhof and Heederik, 2003). The recharge is performed by diverting available water (e.g. reclaimed, storm water, river water) into the pond and letting it infiltrate naturally from the top surface to the underlying aquifer.

\footnotetext{
* Corresponding author. Fax: +34 934017251.

E-mail address: daniele.pedretti@upc.edu (D. Pedretti).
}

In a properly designed SP facility, recharge is limited by the infiltration capacity $\left(I_{c}\right)$ of the soil. $I_{c}$ is defined as the capacity of the soil to allow water to percolate under steady flow conditions driven exclusively by gravity. $I_{c}$ varies depending on the specific conditions of the system, and thus must be defined for realistic recharge conditions by site characterization experiments. Shallow water depths are typically preferable (Bouwer, 1988).

$I_{c}$ varies in space and time due to soil heterogeneities, clogging processes and temperature fluctuations, as well as other processes (Bouwer, 2002; Perez-Paricio and Carrera, 1999). As $I_{c}$ is mostly controlled by the first few centimeters of soil, a priori estimation of infiltration capacity of the topsoil is required to guarantee successful long-term performance of AR practices. Counter examples where the top few centimeters are not the controlling factor can be found when low permeability continuous layers exist at some depth or when the infiltration process leads to a hydraulic connection between the bottom of the pond and the mound formed below the pond (Bouwer, 2002).

Complete and detailed characterization of $I_{c}$ of a given area is helpful for optimal facility management and risk assessments (e.g. Pedretti et al., 2012; Bolster et al., 2009). Because of temporal processes that influence $I_{c}$, it should be re-evaluated or measured 


\begin{tabular}{|c|c|c|c|}
\hline \multicolumn{4}{|c|}{ Nomenclature } \\
\hline$I_{c}(\mathbf{x}, t)$ & local infiltration capacity $\left[\mathrm{LT}^{-1}\right]$ & $a_{X}$ & single bands regression coefficient (slope) \\
\hline$K_{s}(\mathbf{x}, t)$ & local saturated hydraulic conductivity $\left[\mathrm{LT}^{-1}\right]$ & $b_{X}$ & single bands regression coefficient ( $y$-intercept) \\
\hline$m(X)$ & mean pixel value for the $X$ channel in an image & $\varepsilon_{X}$ & single band regression error \\
\hline$\sigma(X)$ & $\begin{array}{l}\text { standard deviation of the pixel values } X \text { channel in an } \\
\text { image }\end{array}$ & $\begin{array}{l}\overrightarrow{I_{c}} \\
S_{j}\end{array}$ & $\begin{array}{l}\text { pond-scale infiltration capacity }\left[\mathrm{LT}^{-1}\right] \\
\text { double-ring test site }\end{array}$ \\
\hline $\begin{array}{l}\bar{\mu}_{j} \\
r_{2}^{2}\end{array}$ & $\begin{array}{l}\text { weighted average } \mu_{X, j} \text { among the } X \text { bands } \\
\text { Pearson's regression coefficient }\end{array}$ & $X$ & band or channel of the image: Red (R), Green (G) or Blue \\
\hline$a$ & multiband regression coefficient (slope) & $\mu_{i, X}$ & average pixel value within the $3 \times 3$ window around the \\
\hline$b$ & multiband regression coefficient ( $y$-intercept) & & experimental $j$ th location in the $X$ band \\
\hline$\varepsilon$ & multiband regression error & $\sigma_{\mu_{j, X}}$ & standard deviation referred to $\mu_{X, j}$ \\
\hline$\sigma_{\bar{\mu}_{j}}$ & multiband standard deviation referred to $\bar{\mu}_{j}$ & & \\
\hline
\end{tabular}

periodically. In addition, $I_{c}$ is strongly related to local soil hydraulic properties, such as the saturated hydraulic conductivity $K_{\varsigma}$ (Langhans et al., 2011). In practice, $K_{s}$ is known to be highly heterogeneous in space (e.g. Dagan, 1989) and a large number of dense points could be required for a proper and complete characterization. Hydrodynamic characterization of soils via direct surveys can be prohibitively expensive and time consuming, or at times even technologically unfeasible.

Recharge is usually evaluated in homogeneous or homogenized areas under flooding conditions driven by rainfall. A large number of methods exist to evaluate recharge of water, e.g. energy or

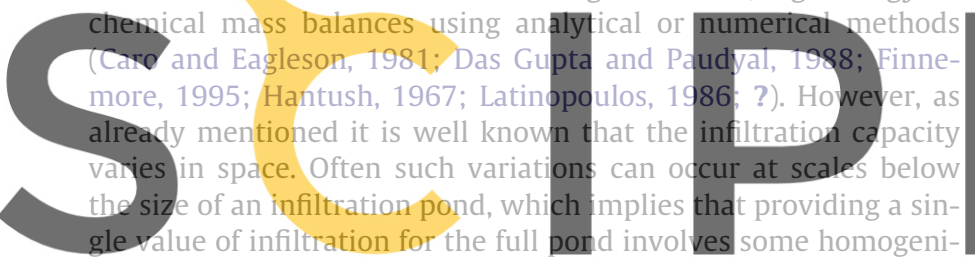
zation process. In effect some representative equivalent infiltration value is used instead of the local $I_{c}$ map.

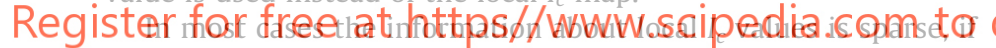
not non-existent. Thus, it may be desirable to rely on secondary information using geophysics, remote sensing, image analysis, or any combination of the above. These methods provide dense information over large scales about (secondary) variables that are related to the (primary) variable of interest. The secondary variables' spatial structure can be more easily evaluated and used to infer that of the primary variable. In fact, variograms or covariance functions about the secondary variables can be implemented to study the spatial structure of primary data (e.g. Gooverts, 1997).

Remote sensing is a relatively well-understood, successful and cost-effective solution to obtain qualitative estimations of recharge or related hydrogeological variables over large scales (e.g. Saraf and Choudhury, 1998; Granger, 2000; Milewskia et al., 2009). However, very few cases in the literature have documented the use of such approaches for quantitative assessments of infiltration capacity. The use of photographic images is restricted to a few studies (e.g. Chica-Olmo and Abarca-Hernandez, 2000; Reddy et al., 1989). Historically there has been a major economic barrier as the acquisition of a typical sequence of satellite images analysis (Bons and Jessell, 1996), was a prohibitively expensive step.

This situation has changed in the recent years. Today, satellite and aerial images of relatively high quality can be obtained at a high resolution and affordable prices (or often no cost) from a variety of sources such as popular Internet-based map providers, cartographic or geological surveys, military research institutions, national and international space agencies, etc.

Satellite or aerial images can cover entire geological basins, and so can be extremely useful for hydrological studies. Often they can be obtained at different resolutions (supports). An image is composed of a fixed number of pixels with varying intensities. Digital images can be made up of several bands (or 'channels'), both in the visible range of colors (red to blue colors) and of non-visible bands (such as the infrared one). The combination and superposition of the visible colors give rise to the typical image one observes on a computer screen. In a single band, the relative intensity of each pixel depends on the electromagnetic energy reflected by the land surface. This is then processed by an acquisition device with a given sensitivity. Understanding the interaction between soil reflectance and the acquisition device is key to deriving information from remote-sensing data (Goetz et al., 1985)

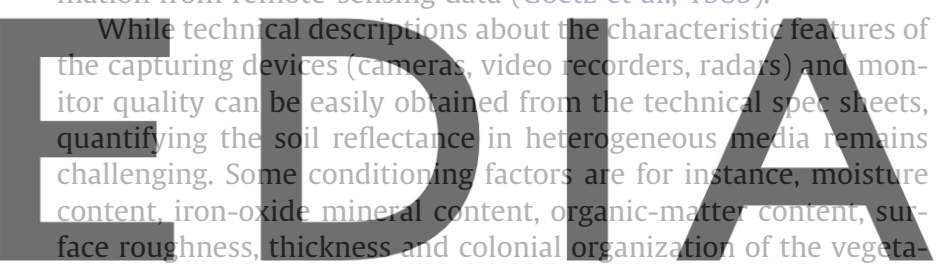

tion canopy and grain structure and organization (see Irons et al., 1989: Okin and Painter, 2004 for details).

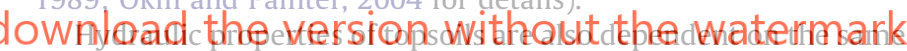
factors as soil reflectance. For instance, the characteristic grain size of a soil is related to the soil permeability (Hazen, 1882; Vukovic and Soro, 1992), as well as the soil porosity (Kozeny, 1927; Carman, 1938; van Genuchten, 1980). Moisture content is also influenced by both clay and organic-matter content. All this reasoning suggests that soil reflectance can be used to obtain information about hydraulic parameters of the topsoil.

The goal of this paper is to explore the potential use of images as an efficient, low-budget and fast method to assess $I_{c}$. We aim to build a relationship between pixel intensities and hydraulic properties in order to estimate $I_{c}$ over large domains using satellite images. As an illustrative case, we study a case study based on a pilot SP facility in the municipality of Sant Vicenç dels Horts (Barcelona, Spain) located in the silico-clastic and highly heterogeneous Llobregat alluvial aquifer.

The paper is organized as follows: Section 2 describes the site and the available experimental data on $I_{c}$; Section 3 discusses the image analysis; Section 4 shows an application of the proposed methodology; and finally, Section 5 addresses a final discussion about the physical meaning of the correlation encountered in the example and about the limitations of this approach.

\section{The artificial recharge facility in Sant Vicenç dels Horts}

A SP was constructed in the municipality of Sant Vicenç dels Horts near Barcelona to study managed artificial recharge practices in the Llobregat River Lower Valley aquifer. The purpose of this pilot area is as a research facility to study the fate of 


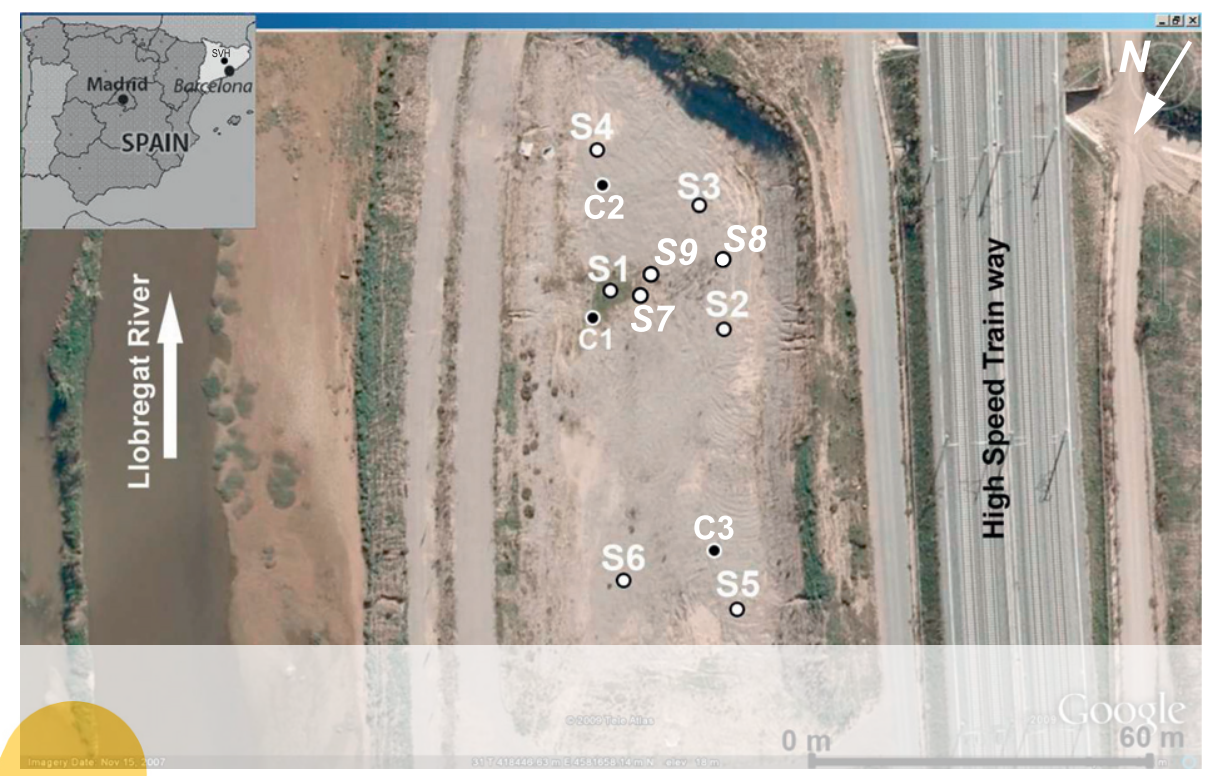

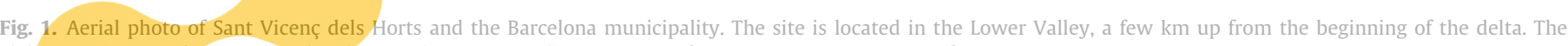
Llobregat River can be traced in the picture. The UTM coordinates are 31T [418446.63 N, 4581658.18 E].

micropollutants during infiltration practices. The facility is located in the prodelta region of the Llobregat River. The site is centered at UTVI coordinates 418446.63 North and 4581658.18 East (zone 31T). Different high-resolution satellite he site at different years. Fig. 1 shows public through a popular Internet-based on November 15 th, 2007 ology of the area is a sequende of fine- and coarse-grained silico-clastic materials, deposited according to the evolution of the paleoriver. The deposition of fine-grained materials occurs in low energy streams (minimum on the alluvial planes),

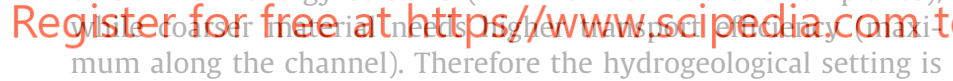
composed of sandy-gravel or gravelly-sand (depending on the proportion of the average grain sizes), separated by non-continuous fine-grained layers. At the scale of the pond, the unsaturated zone has a thickness of between 8 and $10 \mathrm{~m}$. The excavation of the pond ranges from 4 to $6 \mathrm{~m}$ below the actual ground surface, on the western edge of the Llobregat River. A series of field experiments were performed in the SP to assess the local heterogeneities of the topsoils. In the following sections, we summarize two of the most significant activities, the vertical geological description of the ground surface using open pits and a campaign of double rings infiltrometer tests. Both were performed before any MAR activity was carried out at the site (only natural rainfall actually infiltrated during this time).

\subsection{Vertical geological profiles of topsoils}

Three open pits were dug to study the vertical distribution of the geological materials at the upper meter measured from the bottom of the pond. Additionally, samples were taken to obtain the granulometry curve of the different materials described in the open pits. This enabled the qualitative inference of the hydraulic properties of the formation. Fig. 2 shows three vertical profiles obtained at locations $\mathrm{C} 1-\mathrm{C} 2-\mathrm{C} 3$ (see Fig. 2). Visual abrupt changes of soil color (seen in the field) are marked in the figure by solid lines. These changes indicate that soil moisture content and grain distributions are layered in the top sections. Specifically, for C1, the 30-cm-thick top layer displays high moisture, clay and organic content, overlapping the other deeper layers which show coarse- grained materials at lower moisture content. Such differences are visible in the left most photo of Fig. 2: the upper horizon is clearly darker than the rest of the outcrop. Outcrops from pits C 2 and C3
show similar horizontal layering. In this dase, fine-graindd materi-
als and organic content were not observed in the outcrop; the ver-
tical variability is due to changes in sand or gravel relative content.
(\$ee Fig. 3.).
Just by looking at Fig. 2 it follows that there shguld be a corre-
lation between soil color and permeability, dark pixels being representative of the less permeable materials. This proposed correlation is explored in Section 3

\section{download the version without the watermark}

\subsection{Field measurements of topsoil local infiltration capacity}

Six double-ring infiltrometer tests (Bouwer, 1986) were performed in February 2009 on the topsoil of the pond. The location of these experiments (S1-S6 points in Fig. 1) was randomly-selected. A double-ring infiltrometer technique was used. This technique has been well documented (Bouwer, 1986) for the direct measurement of infiltration rates and its applicability has been assessed and validated for several ground conditions (e.g. Bodhinayake et al., 2004).

We briefly describe the method here. The device consists of two concentric thin-walled metal cylinders, with an approximate height of $40 \mathrm{~cm}$, in which a falling head test is carried out. The test consists of three parts: (a) the rings are pushed into the first (5-10) centimeters of topsoil with minimum soil disturbance; (b) both rings are filled with water to the same initial level; (c) the change in water level (decrease) in the inner ring is measured over time. The purpose of the external ring is to minimize lateral flow occurring under the internal ring and ensures primarily vertical flow. After a standard time of about $2 \mathrm{~h}$, the soil is saturated and the infiltration rates (i.e., changes of water heights versus variable time intervals) tend asymptotically to a quasi-steady constant value. The actual infiltrated volume versus time curve is interpreted by means of a modified Kostiakov method (Smith, 1972). Vertical infiltration rate is then determined by the amount of water poured into the inner ring per unit of surface area and time. The inner ring diameter is $0.4 \mathrm{~m}$ and as such our tests provide the infiltration capacity of the S-location over a support area of $0.13 \mathrm{~m}^{2}$. 


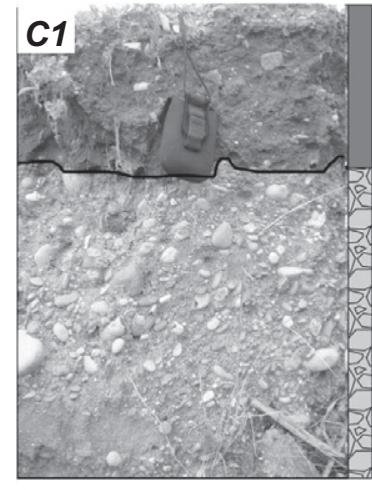

mainly coarse content

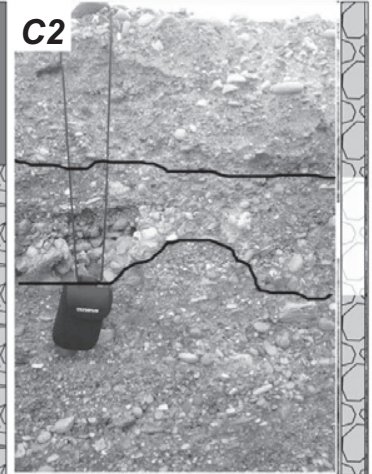

mixed coarse and fine content

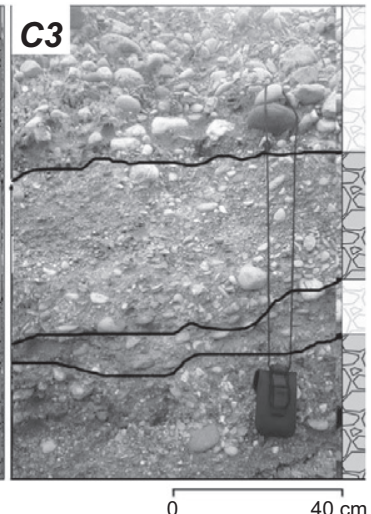

mainly fine content

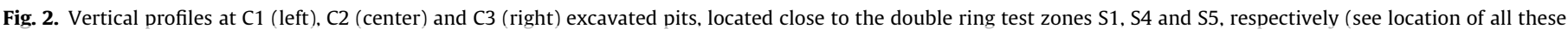
points in Fig. 1). The right side of each picture shows the geological stratigraphic columns (legend at the bottom).

For illustrative purposes we plot the infiltration curves for three locations (S1, S2 and S6) in Fig. 3. These three are representative of the low (S1), middle (S2) and high (S6) rate infiltration areas. Complete results are summarized in the first two columns of Table 1. Note that local infiltration rates span over at least two orders of magnitude in this domain.
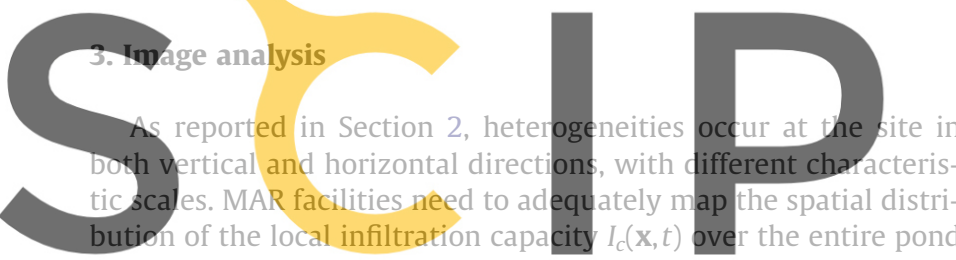
since we are interested in total recharge as a function of time (i.e the spatially-averaged infiltration capacity $\left.\bar{I}_{c}(t)\right)$.

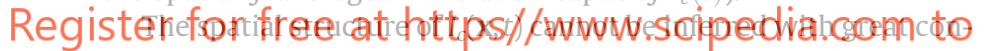
fidence only from the information obtained at a few sparsely distributed data points (such as S1-S6 from the February 2009 campaign). Additional information, either on $I_{c}(\mathbf{x}, t)$ or eise on a related secondary variable must be sought for this purpose. While the former can be expensive or challenging for a variety of reasons, secondary information can be used to condition the primary information.

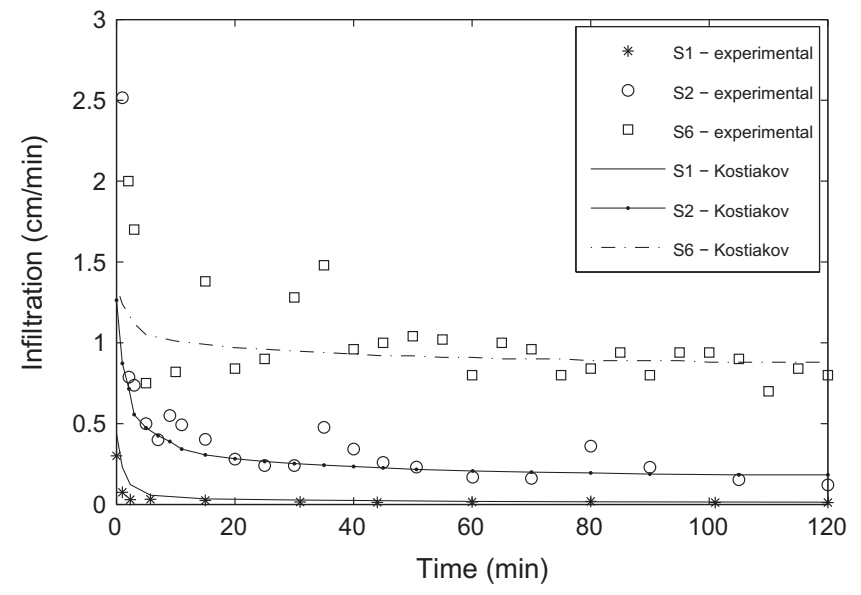

Fig. 3. Experimental measurement of local infiltration rates from double-ring infiltration tests and interpretation using the modified Kostiakov method, at three location $\mathrm{S} 1, \mathrm{~S} 2$ and $\mathrm{S} 6 . I_{c}$ is calculated as the infiltration rate measured after $120 \mathrm{~min}$. The analytical curves proposed by Kostiakov (Smith, 1972) are shown for reference. The actual value used in Table 1 is that inferred from the analytical curve at $t=2 \mathrm{~h}$, rather than the measured values itself, in order to avoid noise.
Secondary variables are typically related to primary variables via mathematical and physically-based models; the density of secondary data is normally sufficient for detailed spatial descriptions, and with some approximations, can be directly used to model the primary information (Journel, 1999). In most cases the correlation between the two variables is not perfect and some error (either correlated or not) must be included in the model.

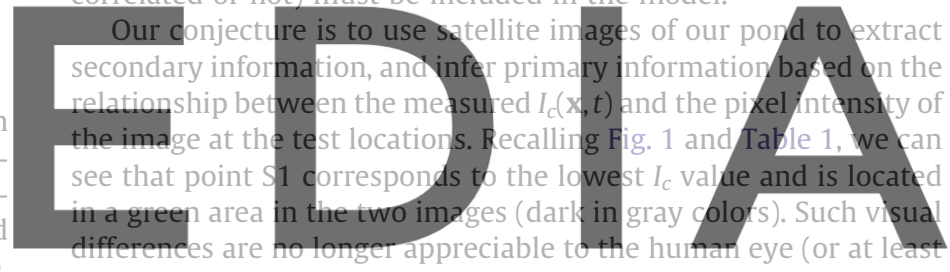

our eyes) for locations with high $I_{c}$ values, since it is more difficult

\section{download the version without the watermark}

Table 1

Field measurements of infiltration capacities $\left(I_{c}\right.$, in $\mathrm{m} / \mathrm{d}$ ) from the double ring tests at the specified locations $\left(S_{j}\right)$ and the correspondent average $\left(\mu_{X, j}\right)$ and standard deviation $\left(\sigma_{X, j}\right)$ of the $3 \times 3$ window pixel values for each $X$ band $(\mathrm{R}, \mathrm{G}$ or B) at the $j$-site $(j=1, \ldots, 9)$. Above, the data refer to the Internet-provided image; below, the data corresponding to the original image are reported. For the full color map, $M_{j}$ is the arithmetic mean of the pixel values when all bands are considered together at the $j$ location, and $w_{j}=$ weight from the regression analysis at the $\mathrm{j}$ location. The infiltration tests for S7, S8 and S9 were performed in June 2009 and have been corrected to the values of February 2009 by means of linear regression (see text).

\begin{tabular}{|c|c|c|c|c|c|c|c|}
\hline \multirow[t]{2}{*}{ Site } & \multirow[t]{2}{*}{$I_{c}$} & \multicolumn{2}{|c|}{ Red band } & \multicolumn{2}{|c|}{ Green band } & \multicolumn{2}{|c|}{ Blue band } \\
\hline & & $\mu_{\mathrm{R} j}$ & $\sigma_{\mathrm{R}, j}$ & $\mu_{\mathrm{G}, j}$ & $\sigma_{\mathrm{G}, j}$ & $\mu_{\mathrm{B}, j}$ & $\sigma_{\mathrm{B} j}$ \\
\hline \multicolumn{8}{|c|}{ Internet image } \\
\hline S1 & 0.2 & 94.1 & 2.29 & 98.9 & 1.83 & 77.6 & 5.69 \\
\hline $\mathrm{S} 2$ & 2.6 & 179.1 & 1.83 & 168.1 & 4.39 & 160.3 & 4.82 \\
\hline S3 & 2.9 & 181.1 & 4.48 & 171.0 & 0.60 & 160.0 & 9.16 \\
\hline S4 & 3.3 & 187.3 & 0.50 & 177.9 & 5.21 & 166.4 & 8.81 \\
\hline S5 & 12.9 & 196.9 & 4.98 & 178.2 & 1.58 & 178.2 & 5.18 \\
\hline S6 & 12.6 & 196.0 & 1.58 & 185.0 & 5.05 & 176.0 & 6.17 \\
\hline *S7 & 0.17 & 103.2 & 5.21 & 104.7 & 1.80 & 84.7 & 4.53 \\
\hline *S8 & 3.04 & 183.3 & 1.80 & 172.3 & 5.42 & 162.7 & 5.00 \\
\hline *S9 & 0.75 & 142.4 & 5.41 & 132.4 & 7.12 & 120.4 & 9.28 \\
\hline \multicolumn{8}{|c|}{ Original image } \\
\hline $\mathrm{S} 1$ & 0.2 & 91.2 & 6.96 & 93.3 & 4.53 & 71.9 & 2.03 \\
\hline S2 & 2.6 & 193.5 & 7.10 & 179.1 & 4.83 & 151.2 & 245 \\
\hline S3 & 2.9 & 179.6 & 10.32 & 191.6 & 6.94 & 156.2 & 4.39 \\
\hline S4 & 3.3 & 181.4 & 11.89 & 160.9 & 7.24 & 145.2 & 0.52 \\
\hline S5 & 12.9 & 198.9 & 4.68 & 193.1 & 5.18 & 160.9 & 5.21 \\
\hline S6 & 12.6 & 202.4 & 6.64 & 203.3 & 4.16 & 179.4 & 1.58 \\
\hline${ }^{*}$ S7 & 0.17 & 83.8 & 4.47 & 86.3 & 3.77 & 58.6 & 5.22 \\
\hline *S8 & 3.04 & 198.0 & 5.09 & 195.0 & 5.91 & 150.3 & 1.99 \\
\hline *S9 & 0.75 & 141.9 & 10.04 & 149.0 & 7.96 & 146.4 & 5.41 \\
\hline
\end{tabular}


to distinguish bright colors. Nonetheless a relationship appears to exist.

\subsection{Description of the digital data for the Sant Vicenç dels Horts site}

We analyze the relationship that exists between $I_{c}(\mathbf{x}, t)$ and the pixel intensities of two types of digital images, coming from two different sources. The first is obtained by an Internet-based map software, while the second is an image provided by the local cartographic institute. While the latter may suppose an initial, sometimes prohibitive, investment, we aim to achieve good-quality information with former, which is completely free and is suitable for fast and cheap assessments.

In our first case, the Internet image (the same in Fig. 1) is obtained by capturing an image as a standard RGB (Red, Green and Blue channels) raster (saved in TIFF file format). For convenience, we choose to work only on a rectangular portion of the image (marked in Fig. 1), which corresponds roughly to an area of $45 \times 100 \mathrm{~m}^{2}$. This area is represented by $326 \times 730$ pixels, so that each pixel corresponds to $0.02 \mathrm{~m}^{2}$. The raster is then composed of a total of $2.38 \times 10^{5}$ pixels per band. This method is deliberately quick and simple to illustrate that it can be cost effective and quick. However, it must be noted that the method can suffer from a lack of precise information due to image compression, resolution problems and filtering that may have been performed by the Internet map software programmer or with other processing software to save the TIFF file. In this case, this provider does not appear to pro-

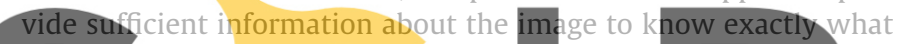
filtering processes and image editing we On the other hand, the second digital space at the exact same time is provided tographic Institute of Catalonia (ICC)
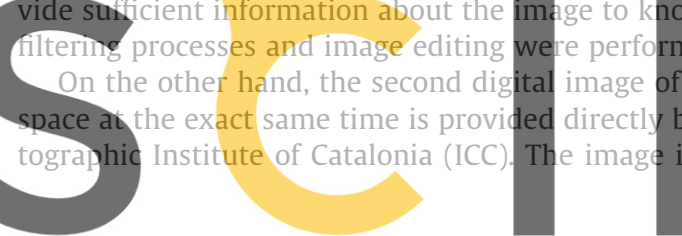

Red band

Registep4for free rat https//www.scipedia.com to
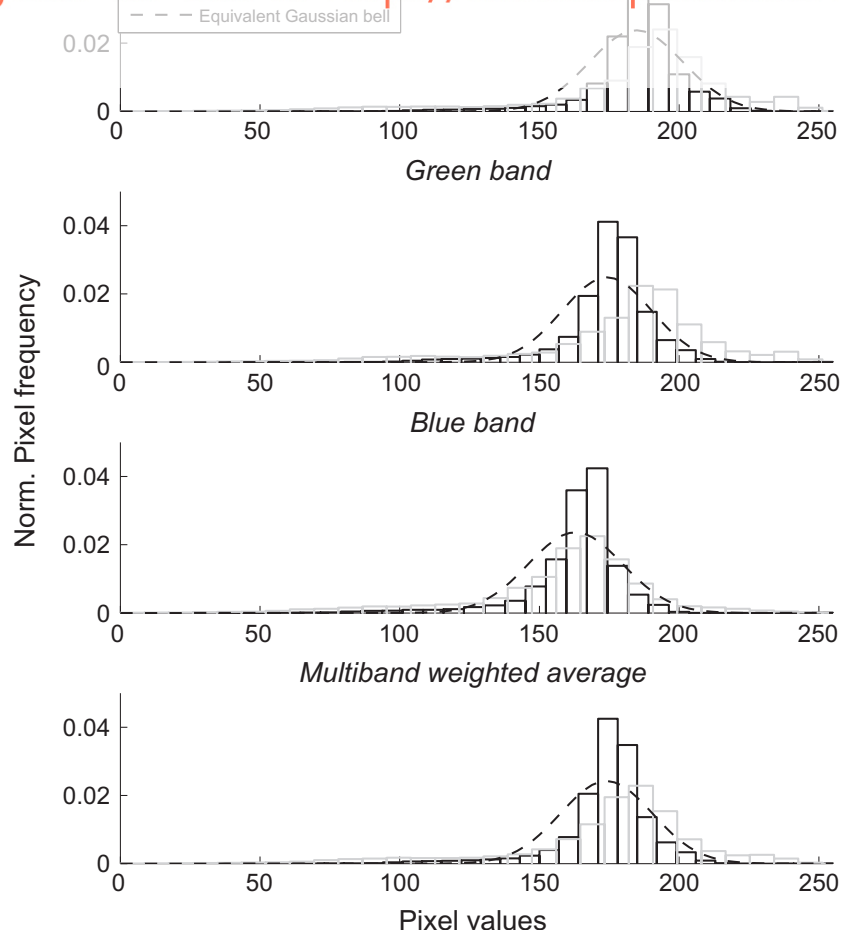

Fig. 4. Density of pixels in the three bands of the sampled image. A Gaussian curve (dotted line) is fitted to the histograms of the Internet-provided images to test visually the symmetry of the distributions.
RGB bands raster, in non-compressed TIFF format, with a pixel resolution of $25 \mathrm{~cm}^{2}$. We refer to this image as the 'original' image, since all specifications are well known from the source. In fact, it is known that the Internet map provider used images from the ICC to build their software and images.

For comparison purposes, both digital images are taken as the same moment in time and considered the same working area. The color depth of both digital images is of 8 bits, offering $2^{8}=256$ values on intensity per channel. The range is from 0 (black $=$ minimum intensity) to 255 ( white $=$ maximum intensity).

Fig. 4 displays histograms of the pixel intensities for each $X$ color channel $(X=\mathrm{R}, \mathrm{G}$ or $\mathrm{B})$, and histograms of averaged values over the three bands, for both images. For the Internet image, the color intensities in all channels do not cover the entire range of possible values, demonstrating a potential filtering that took place. Moreover, the statistics for each of the three channels are different. Let $m(X)$ and $\sigma(X)$ be respectively the mean and the standard deviation of the pixel values for each $X$ channel, calculated from the histograms. The red ( $R$ ) color intensities range from 35 to 225 with $m(R)=184.64$ and $\sigma_{R}=16.8$. The Green $(G)$ and Blue $(B)$ channels exhibit similar standard deviations $(\sigma(\mathrm{G})=16.0$ and $\sigma(\mathrm{B})=16.9)$ but with smaller means $m(G)=174.1715$ and $m(B)=162.4)$. Notice that the actual distribution of pixel data is quite symmetric, showing slightly positively skewness and a leptokurtic effect. To test it visually, we plot an equivalent Gaussian bell with the same $m(X)$ and $\sigma(X)$ in each band of the Internet based image.

The original ICC-provided image exhibits similar histograms of

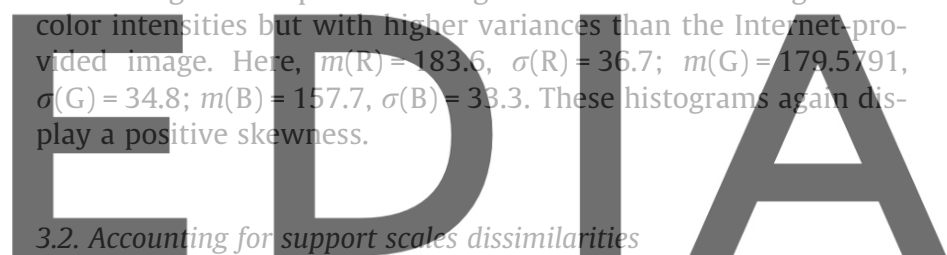

A quantitative analysis of the correlation between $I_{c}(x, t)$ and

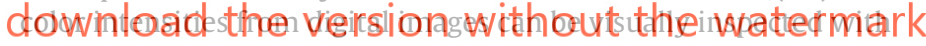
a scatter plot. However, the spatial support of the infiltration test

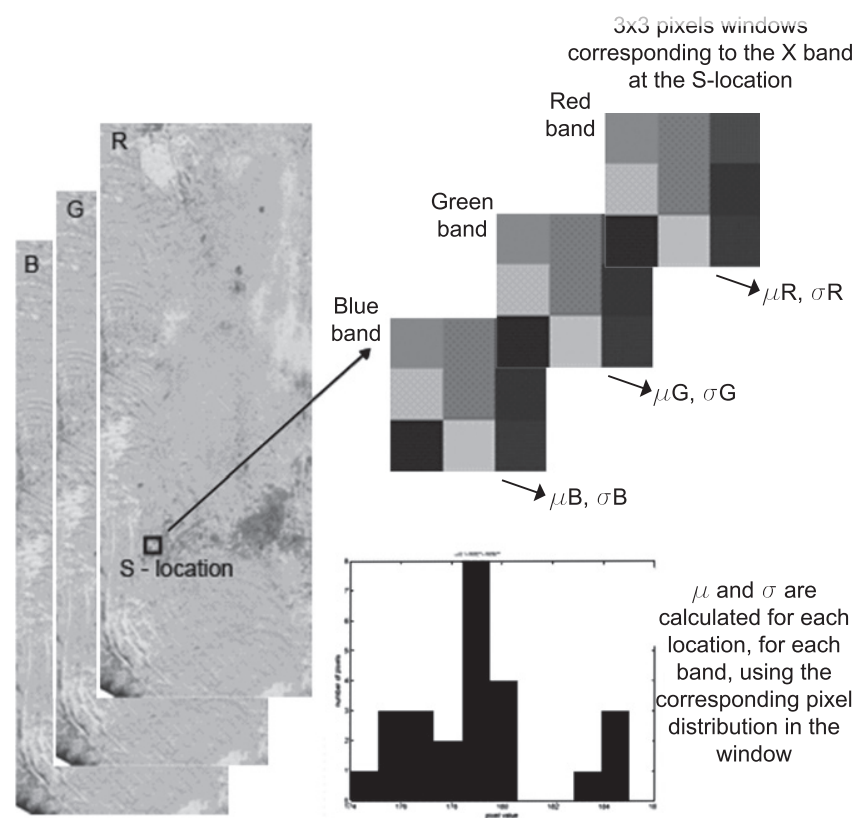

Fig. 5. Assigning pixel intensities to a given test $j$-location $\left(S_{j}\right)$ for each $X$ band $(\mathrm{R}, \mathrm{G}$ or $\mathrm{B})$. The point location of the test is assigned to a given pixel in the image. Intensity values are obtained as the average over the $3 \times 3$ pixel window centered at this reference pixel $\left(\mu_{j, X}\right)$; the standard deviation $\left(\sigma_{\mu_{j X}}\right)$ of the 9 pixel intensities referred to $\mu_{j, X}$ are reported in Table 1 . 
$\left(0.13 \mathrm{~m}^{2}\right)$ is rather large compared to the pixel resolution (around $0.02 \mathrm{~m}^{2}$ ). In order to make comparable predictions we averaged the pixel intensities in the digital images over a window of $3 \times 3$ pixels. The procedure is graphically explained in Fig. 5). For each $S_{j}$ site (S1-S9) and for each $X$ band we estimated the local mean $\mu_{j, X}$ and relative local standard deviation $\sigma_{\mu_{j x}}$ over a $3 \times 3$ pixel window centered at $j$. The variance is a measure of the quality of the estimation, which depends on the variations observed within the given window. These values are reported in Table 1 .

\subsection{Multiband regression model}

We formulate a general regression model which considers the quality of data varying with each observation location in each color channel. This is done to include different degrees of confidence which are implicitly associated with the regression model of each color channel. In our case (Fig. 4), we see that, for each observation window and image, the mean pixel values $\left(\mu_{j, X}\right)$ are in most cases similar among color channels. However, the quality of the estimation of $\mu_{j, X}$ given by its standard deviation $\sigma_{\mu_{i x}}$ varies with the observation, so that the regression coefficients depend on the image source and color channel. In an attempt to incorporate these effects, we generalized the previous methodology as it follows. Noting that the Pearson's correlation, $r_{X}^{2}$, measures the goodness of fit to a linear regression model in each $X$ band, for each $j$-point we estimated the color intensity as a weighted average over the
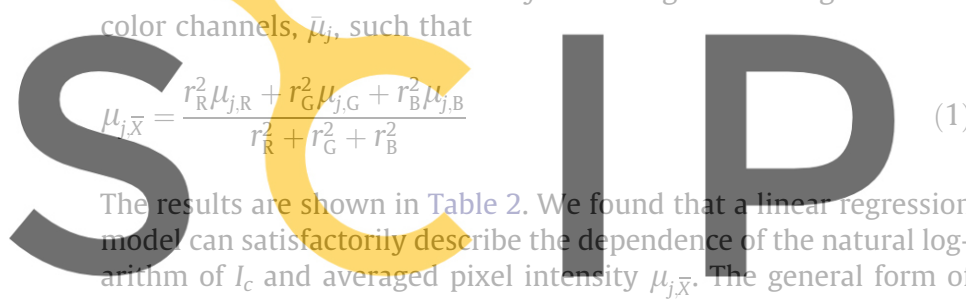

the equation is as inversely proportional to the quality of the local multiband estimation $\bar{\mu}_{j}$, such that

$\bar{w}_{j}=\frac{1}{\sqrt{\sigma_{\bar{\mu}_{j}}^{2}}}$

where $\sigma_{\bar{\mu}_{j}}^{2}$ is the multiband estimation variance calculated as

$\sigma_{\bar{\mu}_{j}}^{2}=\frac{r_{\mathrm{R}}^{4} \sigma_{\mu_{j, \mathrm{R}}}+r_{\mathrm{G}}^{4} \sigma_{\mu j, \mathrm{G}}+r_{\mathrm{B}}^{4} \sigma_{\mu j, \mathrm{~B}}}{\left(r_{\mathrm{R}}^{2}+r_{\mathrm{G}}^{2}+r_{\mathrm{B}}^{2}\right)^{2}}$,

Estimates of the variances for all measurements are reported in Table 1. Fig. 6 shows the resulting fitted regression models for each digital image source. For Internet-provided image

$\ln \left(I_{c}\right)=0.0380 \bar{\mu}-5.244 \quad r_{\bar{X}}^{2}=0.85$,

while for the original image we obtain

$\ln \left(I_{c}\right)=0.0343 \bar{\mu}-4.466 \quad r_{\bar{x}}^{2}=0.93$.

\subsection{Model validation}

The regression model was validated against three independent double-ring infiltrometer measurements obtained during a second campaign. Their locations are also denoted in Fig. 1 and marked by S7, S8 and S9 tags. These new experiments were specifically selected to fill gaps in the linear regression model. The infiltration

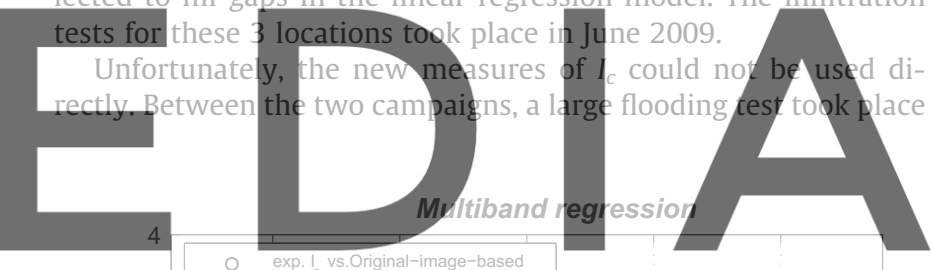
ginal-image-based exp. tovs. Internet-image based

\section{Register fof free at https//www.scipedia.com tol d}

Note that color intensities were found to follow a quite symmetric distribution (Fig. 4). Despite they do not show an exactiy Gaussian behavior we could in principle assume that the related infiltration capacity roughly follows a log-normal distribution, as given by (2). Log-normal distribution model is a typical adopted for hydraulic conductivities in soils (e.g. Freeze, 1975), to which $I_{c}$ strictly depends.

In (2), $\varepsilon$ expresses the model error. Since the quality of the estimates of $\mu_{j, X}$ is not constant across observations, other regression methods such as weighted least squares should be used. In this method, the measurement error is weighted based on its corresponding degree of confidence. Here, we estimated these weights

Table 2

Multiband average $\mu_{j}$ and calculated multiband weight $\left(\bar{w}_{j}\right)$ among the $X$ band at the $3 \times 3$ windows around the $j$ th experimental S-sites $(j=1, \ldots, 9)$. Data refer to the Internet and the original images.

\begin{tabular}{lccccc}
\hline Site & Internet image & & & \multicolumn{2}{c}{ Original image } \\
\cline { 2 - 3 } \cline { 5 - 6 } & $\mu_{j}$ & $\bar{w}_{j}$ & & $\mu_{j}$ & $\bar{w}_{j}$ \\
\hline S1 & 90.1 & 0.50 & 85.7 & 0.18 \\
S2 & 169.2 & 0.34 & 175.1 & 0.19 \\
S3 & 170.7 & 0.28 & 176.1 & 0.12 \\
S4 & 177.2 & 0.34 & 162.9 & 0.11 \\
S5 & 184.4 & 0.24 & 184.8 & 0.21 \\
S6 & 185.6 & 0.32 & 195.4 & 0.18 \\
${ }^{*}$ S7 & 97.4 & 0.24 & 76.5 & 0.25 \\
${ }^{*}$ S8 & 172.8 & 0.30 & 181.7 & 0.20 \\
*S9 & 131.7 & 0.17 & 145.7 & 0.12 \\
\hline
\end{tabular}

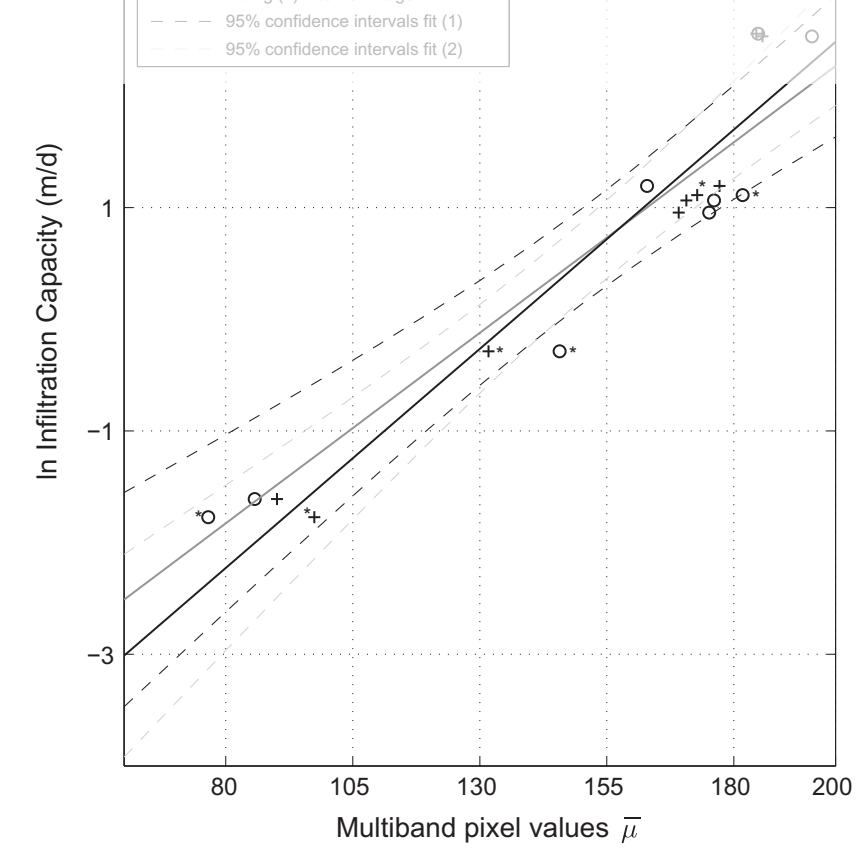

Fig. 6. Linear fitting of the experimental tests of the infiltration capacity $\left(I_{c}\right.$, in natural $\log$ scale) versus the multiband weighted average pixel values $\left(\mu_{\bar{\chi}}\right)$, calculated at the $3 \times 3$ window around the $S_{j}$ experimental site. Weights are given by the relative quality of the information, based on the multiband window variances $\sigma_{i \bar{X}}^{2}$ - see text. The region of confidence is expressed by the $95 \%$ confidence boundaries. 
in the pond, resulting in a net decrease of infiltration capacity due to clogging processes. The impact of flooding was analyzed by repeating the previous infiltration tests at the S1-S6 locations. A good linear relationship was found between the pre-clogged and post-clogged infiltration values, which allowed us to correct the June 2009 data to the values corresponding to February 2009 (see Pedretti et al., 2011 for details). These corrected value are reported in Table 1. In Fig. 6 they are indicated with a star beside the points. We see that they agree quite well with our regression model, lying within the region of confidence (expressed by the $95 \%$ confidence boundaries of the multiband regression model).

\subsection{Single band regression}

A special case of the multiband model is when only single bands are accounted for. Such models (single-band regression models) are a general form of (2) and are especially useful when one specific channel or band provides a better fit than the others (provided physical conditions are fulfilled)

For instance, infrared bands (when available) have been used to evaluate specific patterns of soil moisture (e.g. Price, 1980). This information could be related to some characteristic hydrodynamic property of the soil, thus making the correlation more robust. In our case, we explore the quality of a linear regression for the three visible-color bands, separately in each image. This is simply done by taking the single channels parameters in (2). The single band model is thus

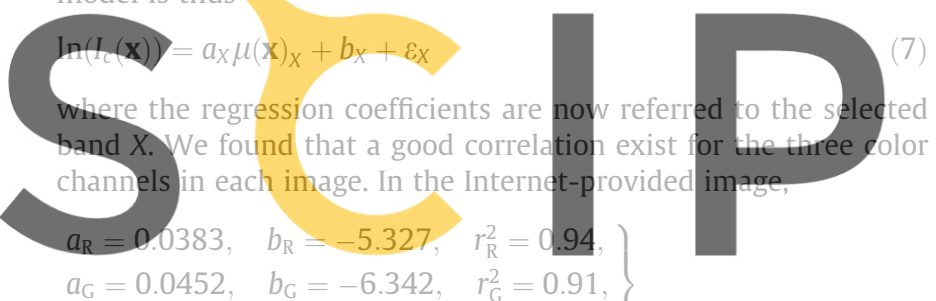

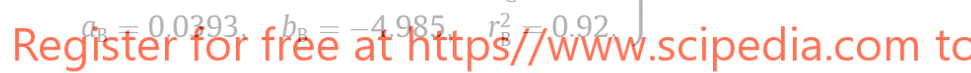
while for the original image,

$$
\left.\begin{array}{lll}
a_{\mathrm{R}}=0.0320, & b_{\mathrm{R}}=-4.586, & r_{\mathrm{R}}^{2}=0.90, \\
a_{\mathrm{G}}=0.0335, & b_{\mathrm{G}}=-4.758, & r_{\mathrm{G}}^{2}=0.878, \\
a_{\mathrm{B}}=0.0350, & b_{\mathrm{B}}=-4.094, & r_{\mathrm{B}}^{2}=0.840,
\end{array}\right\}
$$

We observe that the parameters differ slightly from one other due to small differences in the histogram distributions $(m(X)$ and $\sigma(X))$. However, $r_{X}^{2}$ is greater than $84 \%$ for each of the three channels, which suggests that a good correlation exists for each case. $r_{B}^{2}$ for the Internet image is slightly larger than the for the other cases and perhaps this might suggest this is the preferred image and band. However, given that the differences in $r^{2}$ are so small, in the following, we apply the general multiband model for illustrative purposes.

\section{Estimates of infiltration capacity at the pond scale}

The methodology described above is used to estimate the spatial distribution of $I_{c}$ at the SP pilot site. Results are only shown for the multiband regression model, but in this particular example plots would be qualitatively identical and quantitatively similar using the single-band model. The resulting infiltration map stemming from the multiband regression analysis of the Internet digital image is shown in Fig. 7. The local infiltration capacity is calculated using (2) at each pixel in the whole image. As a way to evaluate the adequacy of the model, we compared estimates of the global infiltration rate as calculated from the Internet image with observations of the total maximum infiltration recorded during a

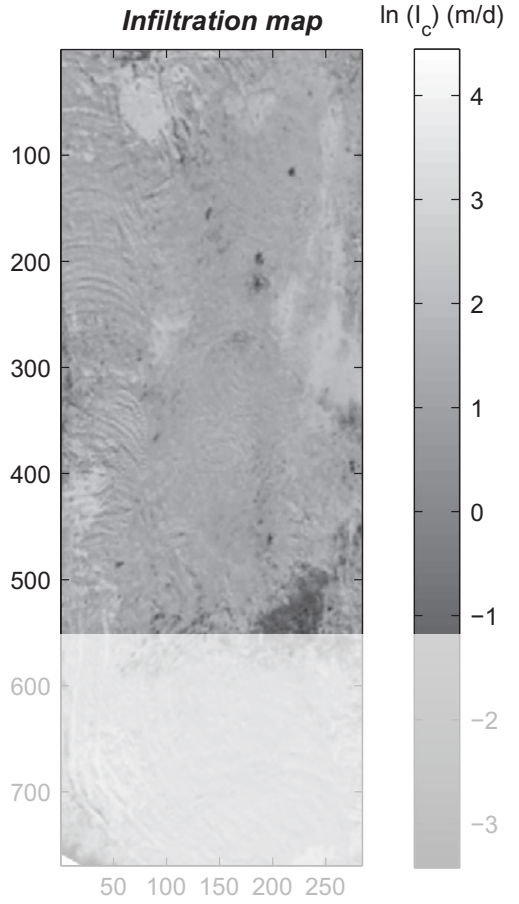

Fig. 7. Map of the local infiltration capacities (in $\mathrm{m} / \mathrm{d}$ ) calculated using the

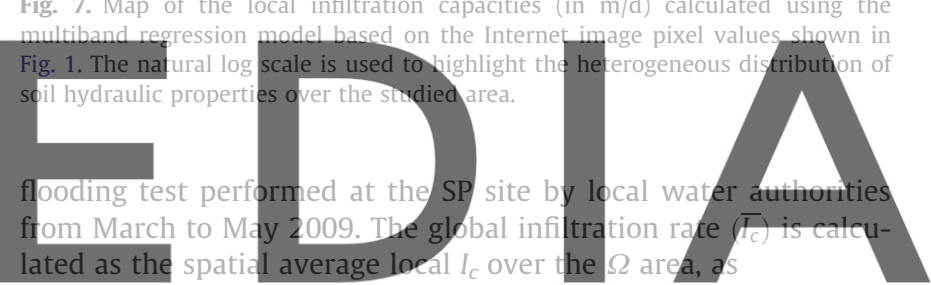

$\overline{I_{c}}=\frac{1}{T} \int I_{c}(\mathrm{x}) d \mathrm{x}$

dowprload the version without the watermark

During this test, experimental value of the total infiltration rate were calculated using a water balance in the pond (conservation of mass in the pond including evaporation). The total maximum infiltration rate was reached after 40 days (when the pond was completely flooded) and was measured to be $3.6 \mathrm{~m} /$ day. Predictions using the multiband model are of $\overline{I_{c}}=4.47 \mathrm{~m} / \mathrm{d}$ for the original image and $\overline{I_{c}}=3.92 \mathrm{~m} / \mathrm{d}$ for the Internet image. We observe that the latter prediction provides a relatively good agreement with the experimental data, as the error is less than $10 \%$. We deem this to be an acceptable error given the trade-off between the cost of the analysis and the estimation error. It is worth noting that a more proper and detailed assessment of errors should follow a rigorous evaluation of several factors, including errors in the calculation of the global mass balance. In the latter case, for instance, the combined effects gas clogging, incomplete pond flooding, errors in the measurements of the discharge rates of entry water, etc. lead to measurement uncertainty. This has not been considered in detail here.

\section{Discussion and conclusions}

Dealing with spatial variability of soil hydraulic variables (like the infiltration capacity) in the field is always challenging and uncertain. This is due to the high cost of in situ site characterization. In this paper we present an alternative and low-cost method to map the infiltration capacity in heterogeneous alluvial formations from satellite images. We find that a relationship between infiltration capacity (measured in some random locations) and 
color intensity of two digital images can be well established to provide the spatial distribution of soil properties such as the infiltration capacity. The method was satisfactorily applied to an artificial recharge pond area close to the city of Barcelona.

The relationship we built appears to be robust, physically justifiable, and satisfies some premises like monotonicity of the correlation functions. In our test images, the ground surface appears not to be affected by objects or other disturbances (for instance, a presence of trees or shadows) that could have modified the natural color or reflectance in portions of the domain. This avoids the need to apply filters to the image to remove such imperfections, which would modify the original pixel organization, structure and intensities.

We justify the physical validity of our relationship by noticing that the image depicts darker portions which have been associated with fine-grained portion of the soils, with substantial organic content and vegetation canopy, whereas brighter colors correspond to areas with cleaner sands and gravels of low fine content and vegetation. It is worth noting that the correspondence of dark soil to dark pixels and vice versa may not be universal (e.g. depending on the considered light spectrum range). Also different soil reflectance can depend on several factors such the type of light, solar ray inclination, time of day, and season. As such, we suggest that this method should be valid for a rapid assessment of areas that are geologically similar to the one we consider and for applications where the ground surface is free of covering materials. Both these conditions are characteristic of typical artificial recharge sites.

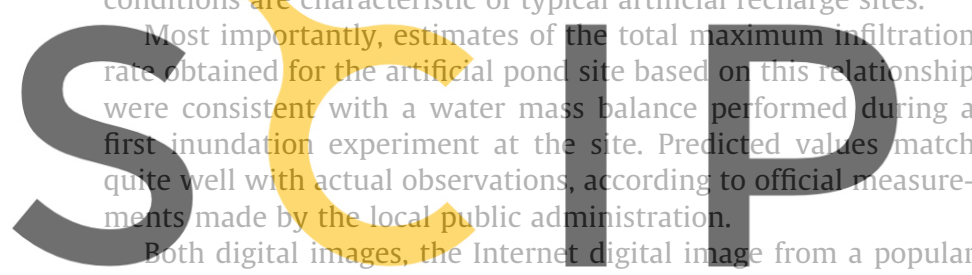
web based provider and the one officially provided by the Catalan Cartographic Institute, gave similar results, highlighting the

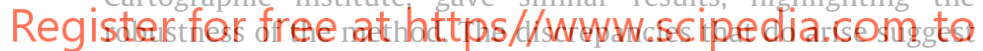
that any estimates should be coupled with an uncertainty analysis to quantify the reliability of this method as compared to other more sophisticated but more expensive ones.

\section{Acknowledgments}

The authors would like to thank Josep A. Gili for helpful discussions in relation to this work. This work was funded by the Spanish Ministry for Science and Innovation through projects RARA-AVIS (ref. GCL 2009-1114), Consolider-Ingenio 2010 (ref. CSD200900065), and HEROS (ref. CGL2007-66748). D.P. would like to further acknowledge the Spanish Ministry of Science and Innovation for funding via the FPU scholarship program (Formation of University Lecturers). M.B. would like to further acknowledge the University of Costa Rica (UCR) and the Spanish Council for Scientific Research (CSIC) for funding through the UCR-CSIC scholarship program.

\section{References}

Aish, A., de Smedt, F., 2004. Modeling of a groundwater mound resulting from artificial recharge in the Gaza Strip, Palestine. In: Water for Life in the Middle East, 2nd Israeli-Palestinian International Conference, Turkey, 10-14 October, 2004.

Asano, T., 1985. Overview: artificial recharge of groundwater. Technical report, Butterworth Publisher, Stoneham, MA. Central Groundwater Board Guide on artificial recharge to groundwater. Ministry of water resources, New Delhi, India.

Bodhinayake, W., Si, B.C., Noborio, K., 2004. Determination of hydraulic properties in sloping landscapes. Tension and double-ring infiltrometers. Vadose Zone J. 3, 964-970.
Bolster, D., Barahona-Palomo, M., Dentz, M., Fernàndez Garcia, D., Sanchez-Vila, X. Trinchero, P., Valhondo, C., Tartakovsky, D.M., 2009. Probabilistic risk assessment applied to contamination scenarios in porous media. Water Resour. Res. 45, W06413. doi:10.1029/2008WR007551.

Bons, P., Jessell, M.W., 1996. Image analysis of microstructures in natural and experimental samples. In: De Paor, Declan G. (Ed.), Structural Geology and Personal Computers, Computer Methods in the Geosciences, vol. 15. Pergamon, pp. 135-166.

Bouwer, H., 1986. Intake rate: cylinder infiltrometer. In: Klute, A. (Ed.), Methods of Soil Analysis. Part 1. Physical and Mineralogical Methods, P. Agronomy, vol. 32. Amer. Soc. Agronomy \& Soil Sci. Soc., America, Wisconsin, pp. 825-844.

Bouwer, H., 1988. Design and management of infiltration basins for artificial recharge of ground water. In: 32nd Annual New Mexico Conference on Ground Water Management, Albuquerque, NM, November 5-6, 1987.

Bouwer, H., 2002. Artificial recharge of groundwater: hydrogeology and engineering. Hydrogeol. J. 10, 121-142. doi:10.1007/s10040-001-0182-4.

Carman, P.C., 1938. The determination of the specific surface of powders. J. Soc. Chem. Ind. Trans 57, 225.

Caro, R., Eagleson, P.S., 1981. Estimating aquifer recharge due to rainfall. J. Hydrol. 53 (1), 185-211.

Cheng, Y., Lee, C.H., Tan, Y.C., Yeh, H.F., 2009. An optimal water allocation for the Ailiao irrigation district in Pingtung Country, Taiwan. Irriga. Drain. Syst. 58 (3), 287-306.

Chica-Olmo, M., Abarca-Hernandez, F., 2000. Computing geostatistical image texture for remotely sensed data classification. Comput. Geosci. 26, $373-$ 383.

Das Gupta, A., Paudyal, G.N., 1988. Estimating aquifer recharge and parameters from water level observations. J. Hydrol. 99, 103-116.

Dillon, P. (Ed.), 2002. Management of Aquifer Recharge for Sustainability: Proceedings of the 4th International Symposium on Artificial Recharge of Groundwater, Adelaide, September 2001. Taylor \& Francis, New York

Finnemore, E.J., 1995. A program to calculate groundwater mound heights, J. Hydrol. 33 (1), 139-143.

Freeze, R.A., 1975. A stochastic-conceptual analysis of one-dimensional groundwater flow in nonuniform homogeneous media. Water Resour. Res. 11

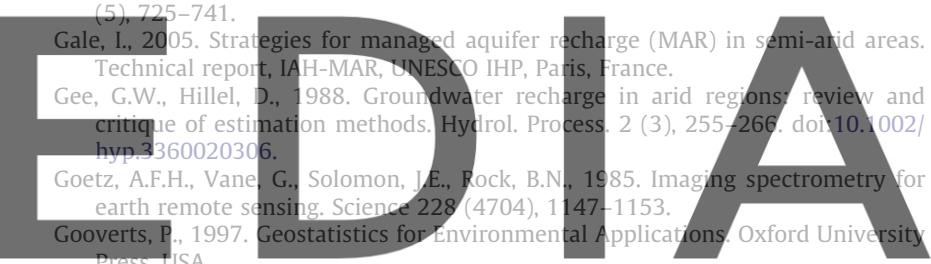

Dagan, G., 1989. Flow and Transport in Porous Media. Sprimger Verlag GmbH \& Co, Heidelberg, Germany.

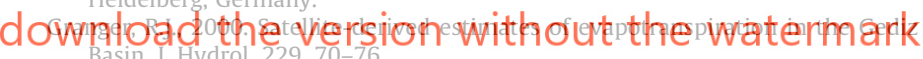

Greskowiak, Prommer, H, Massmann, G., Johnston, C.D., Nutzmann, G., Pekdeger, A., 2005. The impact of variable saturated conditions on the hydrochemistry during altificial recharge of groundwater - a fieid study. Appi. Geochem. 20, 1409-1426.

Hantush, M.S., 1967. Growth and decay of groundwater mounds in response to uniform percolation. Water Resour. Res. 3, 227-234.

Hazen, A., 1882. Some physical properties of sands and gravels, with special reference to their use in filtration. 24th Annual Rep., Massachusetts State Board of Health, Pub. Doc., vol. 34, pp. 539-556.

Hofkes, E.H., Visscher, J.T., 1986. Artificial groundwater recharge for water supply of medium-size communities in developing countries. In: International Reference Centre for Community Water Supply and Sanitation, The Hague.

Irons, J.R., Weismiller, R.A., Petersen, G.W., 1989. Theory and Applications of Optical Remote Sensing. Soil Reflectance. Wiley Interscience, New York.

Jha, M.K., Kamii, Y., Chikamori, K., 2009. Cost-effective approaches for sustainable groundwater management in alluvial aquifer systems. Water Resour. Manage. 23 (2), 219-233.

Journel, A., 1999. Markov models for crosscovariances. Math. Geol. 31 (8), 955-964.

Kozeny, J., 1927. Uber kapillare Leitung des Wassers im Boden. Sitzungsber. Akad. Wiss. Wien 136, 271-306.

Langhans, C., Govers, G., Diels, J., Leys, A., Clymans, W., Van den Putte, A., Valckx, J., 2011. Experimental rainfallrunoff data: reconsidering the concept of infiltration capacity. J. Hydrol. 399 (3-4), 255-262. doi:10.1016/j.jhydrol.2011.01.005.

Latinopoulos, P., 1986. Analytical solutions for strip basin recharge to aquifers with Cauchy boundary conditions. J. Hydrol. 83 (3-4), 197-206.

Milewskia, A., Sultana, M., Yanb, E., Beckera, R., Abdeldayemc, A., Solimand, F., Gelil, K., 2009. A remote sensing solution for estimating runoff and recharge in arid environments. J. Hydrol. 373 (1-2), 1-14.

Okin, G.S., Painter, T.H., 2004. Effect of grain size on remotely sensed spectral reflectance of sandy desert surfaces. Remote Sens. Environ. 89, 272-280.

O'Shea, C.M.J., Baxter, K.M., Charalambous, A.N., 1981. The hydrogeology of the Enfield-Haringey artificial recharge scheme, North London. J. Hydrol. 53 (1), 185-211.

Pedretti, D., Barahona, M., Bolster, D., Fernandez-Garcia, D., Sanchez-Vila, X., Tartakovsky, D.M., 2012. Probabilistic analysis of maintenance and operation of articial recharge ponds. Adv. Water Resour. 36, 23-35. doi:10.1016/ j.advwatres.2011.07.008. 
Pedretti, D., Fernàndez-Garcia, D., Sanchez-Vila, X., Bolster, D., Barahona-Palomo, M., 2011. Spatio-temporal assessment of soil infiltration capacity using physical-based models and geostatistical inference. Stoch. Environ. Resour. Risk Assess. 25, 1065-1075. doi:10.1007/s00477-011-0486-4.

Price, J.C., 1980. The potential of remotely sensed thermal infrared data to infer surface soil moisture and evaporation. Water Resour. Res. 16 (4), 787-795. doi:10.1029/WR016i004p00787.

Perez-Paricio, A., Carrera, J., 1999. Clogging handbook. Technical report, Final report, EU project on Artificial Recharge of Groundwater.

Reddy, C.S.S., Campagna, D.J., Levandowski, D.W., 1989. Digital image processing of multitemporal Landsat data and its applications in ground water exploration. In: Geoscience and Remote Sensing Symposium,. IGARSS'89. 12th Canadian Symposium on Remote Sensing, vol. 2, pp. 544-547.

Saraf, A.K., Choudhury, P.R., 1998. Integrated remote sensing and GIS for groundwater exploration and identification of artificial recharge sites. Int. J. Remote Sens. 19 (10), 1825-1841.

Scanlon, B.R., Keese, K.E., Flint, A.L., Flint, L.E., Gaye, G.B., Edmunds, W.M., Simmers, I., 2006. Global synthesis of groundwater recharge in semiarid and arid regions. Hydrol. Process. 20, 3335-3370.
Smith, R.E., 1972. The infiltration envelope: results from a theoretical infiltrometer J. Hydrol. 17, 1-21.

Stonestrom, D.A., Constantz, J., Ferre, T.P.A., Leake, S.A., 2007. Ground-water recharge in the arid and semiarid Southwestern United States. Technical report, BUS Geological Survey Professional Paper 1703.

Ting, C.S., Tsai, J.M., Chien, M.K., 2002. Pilot study for artificial recharge of groundwater using high-infiltration basins. In: 5th Conference on Groundwater Resource and Water Quality Protection:G45-50 (in English with Chinese abstract).

Tuinhof, A., Heederik, J.P., 2003 (Eds.), Management of aquifer recharge and subsurface storage. Netherlands National Committee - International Association of Hydrogeology, No. 4. NNCIAH Publication.

van Genuchten, M.T., 1980. A closed-form equation for predicting hydraulic conductivity of unsaturated soils. Soil Sci. Soc. Am. J. 44, 892-898.

Vukovic, M., Soro, A. (Eds.), 1992. Determination of Hydraulic Conductivity of Porous Media from Grain-Size Composition. Water Resources Publications, Littleton, CO.
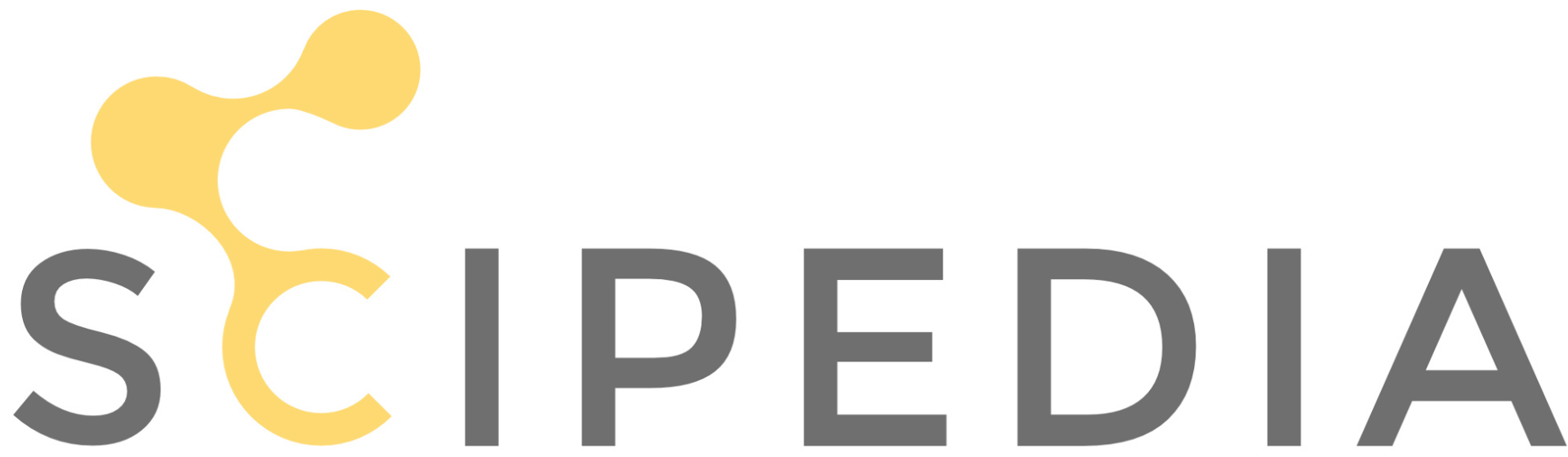

Register for free at https//www.scipedia.com to download the version without the watermark 